\title{
Forewarning of Content and Involvement: Consequences for Persuasion and Resistance to Persuasion
}

\author{
Hong Chyi Chen \\ Grand Valley State University \\ Richard Reardon and Cornelia Rea \\ University of Oklahoma \\ AND \\ DAVID J. MoORE \\ University of Michigan
}

Received December 14, 1990

\begin{abstract}
Two experiments were conducted to advance our understanding of the effects of forewarning on persuasion. In Experiment 1, personal involvement, warning of message content, and distraction during the forewarning-message interval were manipulated. The results indicated that if warned subjects were personally involved with the attitude issue, they became resistant to the persuasive appeal when they were not cognitively distracted after warning. In contrast, when subjects were not personally involved, they were susceptible to the appeal regardless of levels of warning and distraction. In Experiment 2 manipulation of message strength was added to the three factors of Experiment 1 . The results revealed that subjects in high involvement conditions were better able to differentiate the strength of the message (i.e., rate the strong message to be more persuasive than the weak one) than those in low involvement conditions; however, this was true only when the subjects were unwarned, or were warned but distracted. When warning was not followed by distraction, the subjects in high involvement conditions showed resistance to the strong message as well as the weak one. In low involvement conditions subjects were more persuaded in general, but when the warned were not distracted, they seemed to agree more with the strong message than with the weak one. Measurements of postmessage thoughts in both experiments indicated
\end{abstract}

The authors thank Frank Durso, Alan Nicewander, and Wanda Ward for helpful comments. Please direct correspondence and reprint requests to $\mathrm{H}$. C. Chen, Department of Psychology, Grand Valley State University, Allendale, MI 49401. 
that subjects who showed resistance to the persuasive appeal generated more negative thoughts and fewer positive thoughts, compared with persuaded subjects. The results of the two experiments suggested that personal involvement mediates warned subjects' cognitive responding, and when message recipients are highly involved in a counter-attitudinal communication, warning of message content may trigger cognitive defending, which directs them to process the subsequent message in a relatively biased way, thus increasing resistance to persuasion. Results were discussed in the light of cognitive response approaches to persuasion (e.g., Chaiken, Liberman, \& Eagly, 1989; Petty \& Cacioppo, 1986). (1) 1992 Academic Press, Inc.

As persuasion researchers have recognized, forewarning is a complex phenomenon. The history of work on forewarning now dates back more than 25 years, and although we have learned much, some issues regarding effects and processes surrounding forewarning remain unsettled. Beyond specific concerns for forewarning itself, the complexity of forewarning situations guarantees that such situations will be rich in the empirical possibilities they provide persuasion researchers and theorists. The nonforewarned conditions of forewarning experiments are basic persuasion experiments. Then, the forewarning conditions offer additional motivational and information processing contexts that may contribute to our overall understanding of persuasion. In this paper we report on two experiments in which we examine some specific processes and effects of forewarning of content. We also consider what our findings offer to theory development/refinement, with particular reference to current cognitivemotivational models of persuasion (Petty and Cacioppo, 1986; Chaiken, 1980, 1987; Chaiken, Liberman, \& Eagly, 1989).

\section{The Counterargumentation Hypothesis}

Generally speaking, for example, in undergraduate social psychology textbooks, forewarning is presented as a factor that produces resistance to persuasion. Petty and Cacioppo (1986) and earlier, Apsler and Sears (1968) and Papageorgis (1968), have distinguished between forewarning of intent to persuade versus forewarning of the content of the appeal. In the former case, subjects know only that a persuasion attempt is imminent. They do not know what the communicator will say, or which side of the issue the communicator represents. In these instances, it is often assumed that reactance causes message recipients to generate arguments that bolster their own position, and there is some evidence for this (Petty \& Cacioppo, 1979).

Forewarning of content is more subtle and is perhaps closer to most naturally occurring forewarning situations. Recipients know that a message is imminent, and they know roughly or specifically what might be said. Studies have often, but not always, shown that subjects warned in this manner are better able to resist the persuasive appeal of the message than unwarned subjects. Some researchers have proposed that it is not the 
forewarning per se that produces resistance to persuasion, but rather that warned subjects take advantage of the temporal delay preceding exposure to the persuasive message to engage in cognitive counterargumentation. According to this counterargumentation hypothesis, warned subjects are motivated by the warning to consider arguments supporting their own position and refuting antagonistic positions during the temporal delay period; thus, they become more resistant to the subsequent appeal than unwarned subjects. Indirect supportive cvidencc comcs from Freedman and Sears (1965) and Hass and Grady (1975), who demonstrated that as the forewarning-message delay was made longer, resistance to a message increased. Additionally, Brock (1967) found that as forewarnings suggested increasingly discrepant messages, the number of counterarguments subjects generated increased.

In a more extensive test of the counterargumentation hypothesis, Petty and Cacioppo (1977), after a warning manipulation and before exposure to the message, instructed both unwarned and warned subjects to write down either thoughts that naturally occurred to them (actual thoughts) or specific thoughts regarding the topic of the appeal (topic thoughts). The results showed that the warned subjects in actual-thoughts conditions engaged in counterargumentation preceding message exposure. The authors also showed that the unwarned subjects in topic-thoughts conditions were as resistant as the warned subjects to the subsequent appeal. Petty and Cacioppo interpreted their results as consistent with the counterargumentation hypothesis: Directed thought-listing regarding the persuasion topic safeguarded the unwarned subjects from the appeal; the warned subjects were safeguarded by their own cognitive defending, as shown in actual-thoughts conditions.

The thought-listing procedure, however, has been criticized for eliciting listings of thoughts that would not have occurred without the instruction to list thoughts (Miller \& Baron, 1973). Although forewarned subjects in Petty and Cacioppo's (1977) study listed more counterarguments in the "actual-thoughts" condition than subjects who were not forewarned, this may have been because forewarning made knowledge about the topic more available. This greater availability, when combined with demand characteristics of the thought-listing procedure, may have produced the counterarguments. Moreover, the very act of listing thoughts may have caused more resistance to the appeal than would occur in a naturalistic response to forewarning. For instance, it has been found that people who state or write down their opinions before being exposed to the opinions of others are less likely to make subsequent conforming judgments (Kiesler, 1971; Deutsch \& Gerard, 1955). The act of writing down topic-relevant thoughts prior to being exposed to a message may produce similar resistance in persuasion settings by increasing the commitment to a preexisting attitude. 
Distraction has been useful in helping confirm that pivotal role of cognitive responding in other persuasion settings (e.g., Festinger \& Maccoby, 1964; Petty, Wells, \& Brock, 1976; Harkins \& Petty, 1981). A mere temporal delay, without access to refutational arguments, is unlikely to help warned subjects resist the persuasive appeal. When counterargumentation stimulated by a warning of message content is prevented by distraction, a warned subject should be less able to generate counterarguments and should therefore be less resistant to the appeal, compared with a warned but undistracted subject. In the present study, distraction during the delay between forewarning of content and message presentation was used to provide a stronger, more direct test of the counterargumentation hypothesis.

The distraction effect in the present study hinges on an assumption that warned recipients diligently engage in counterargumentation; thus, the distraction effect should not exist if the warned subjects are not motivated to counterargue prior to message exposure. There are findings that show that personal involvement may moderate warning effects (e.g., Apsler \& Sears, 1968; Cialdini, Levy, Herman, Kozlowski, \& Petty, 1976). This suggests that personal involvement in the topic issue should be another factor to be considered to make our test of the counterargumentation hypothesis more complete: A warned person's resistance to a subsequent persuasive appeal may be evident only when the topic of the impending message is important or involving. It follows that cognitive distraction after warning should be important as a disrupter of counterargumentation only when warned subjects are involved and motivated to defend their positions on the issue.

Although, as we mentioned earlier, warning of message content is typically associated with resistance to a persuasive appeal, some research has shown that warned recipients can also become more susceptible to the appeal (e.g., Cooper \& Jones, 1970; Mills \& Aronson, 1965). Message recipients sometimes generate arguments consistent with a counterattitudinal message. McGuire (1985; McGuire \& Millman, 1965) has called this "anticipatory change." He reasoned that message recipients, expecting to be influenced, attempt to maintain self-esteem (i.e., avoid the appearance of being persuasible) by an immediate attitude shift in the direction of the coming message, making it appear that they have held the advocated position all along, or were moving in that direction. Cacioppo and Petty (1979) have outlined this and other attempts to explain susceptibility. They have recently concluded, however, in Petty and Cacioppo (1990), that where susceptibility is found, it can usually be accounted for by either low involvement, because intensity of cognitive processing is low, or high involvement in interaction with other variables that produce a proattitudinal processing bias (e.g., strong rather than weak arguments). We will have more to say about susceptibility later in this introduction. 


\section{Cognitive Elaboration Models}

Current cognitive elaboration models of attitude change [Chaiken's heuristic-systematic model, HSM; Chaiken et al., (1989) and Petty \& Cacioppo's (1986) elaboration likelihood model, ELM] offer a good framework within which to consider the effects of forewarning. Following current trends in cognitive psychology and social cognition, these models hold that issue-relevant processing can be based on simple situational "peripheral" cues or heuristics, or that it can be more "central" or systematic (i.e., involve more elaboration.) Systematic, elaborative processing requires cognitive effort and occupies cognitive capacity. It can be negatively affected by individual differences (e.g., extent of issue-relevant personal knowledge) and situational variables (e.g., distraction). In this more elaborative processing, the processor accesses and scrutinizes information that may be relevant and important to an attitude judgment. Thus message arguments are evaluated carefully and methodically, although not necessarily in an unbiased fashion. Personal knowledge and personal motivations may bias systematic processing and influence interpretation of message arguments.

On the other hand, heuristic or peripheral processing is less effortful and occupies less cognitive capacity. Recipients make judgmental decisions based on simple inferential rules or situational cues (e.g., experts know what they are talking about; if most people hold a particular position, it must be correct; a person in a lab coat must know what he or she is talking about; etc.). This kind of processing is more schematic in that it more extensively involves the instantiation of existing organized knowledge structures. Decisions are made quickly and efficiently, with little absorption of the semantic content of the message. This use of schemata may occur with or without awareness.

An important assumption of cognitive models is that we are motivated to hold valid, accurate (congruent with facts) attitudes. Elaborative and heuristic processing are called on in the service of maximizing confidence in the validity of our attitudes. Because heuristic processing is less effortful, it will be engaged as long as confidence in validity of attitudes is lacking, as long as heuristic cues are available, and when recipients are unmotivated or unable to engage in systematic processing. Systematic processing may be engaged when recipients believe that heuristics will not lead to a sufficient increase in confidence in one's attitude. For example, when an issue is high in personal relevance, presumably recipicnts are unlikely to feel that sufficient confidence can be attained with simple decision rules.

Elaborative and heuristic-peripheral processing can co-occur and can have attenuative, additive, or interactive effects on persuasion. For example, the effects of systematic processing may override that based on 
peripheral cues (the attenuation hypothesis) when motivation to process systematically and ability to do so are high. Heuristic processing may bias elaborative processing by influencing judgments about the credibility of the message. Elaborative and heuristic processing can operate independently of each other. Finally, heuristics may themselves motivate elaboration. In earlier studies, for example, we manipulated forewarning, subject knowledge, and expertise of the communicator (Chen \& Reardon, 1987). The results of that study were not unequivocal, but showed that a heuristic cue (in this case, expertise of the communicator) not only can lead to greater persuasion, as indicated by attitude scales, but also can spur cognitive activity even among low knowledge subjects.

\section{Overview of Experiment 1}

In Experiment 1, we manipulated forewarning, distraction during the forewarning-message presentation interval, and involvement. These have been manipulated previously, but never in the same design (e.g., forewarning and distraction, without cognitive responses, in Apsler \& Sears, 1968; and forewarning and involvement, but within the 'intent to persuade' paradigm, in Petty \& Cacioppo, 1979). When subjects are forewarned, involved, and not distracted, they should generate counterattitudinal arguments and should thus be more resistant to the impending appeal. Distraction should interfere with counterargumentation, rendering the recipients more susceptible to the appeal. When they are not involved, forewarning and distraction should have minimal impact, because motivation to counterargue is low. Persuasion may be less for high involvement-forewarned-undistracted subjects, but greater for high involvement forewarned-distracted subjects. An alternative pattern for low involvement conditions, also consistent with cognitive models, might occur, for example, if forewarning itself acts as a heuristic. We might find that it produces susceptibility in the low involvement conditions; it might also stimulate cognitive activity.

\section{EXPERIMENT 1}

\section{Method}

Subjects. The subjects were 86 undergraduates from the University of Oklahoma who participated as one option of a research familiarization requirement.

Design. The design was a $2 \times 2 \times 2$ factorial with two levels of involvement (high and low), two levels of distraction (distracted and undistracted), and two levels of warning (warned and unwarned).

Procedure. The subjects were tested in small groups of up to 10 . These groups were homogeneous with respect to the distraction variable; however, within sessions, subjects were randomly assigned to warning and involvement conditions. Stimulus materials were presented in the form of a booklet. At the beginning of the experiment, subjects were told that the experiment was actually a survey, and that their responses would be anonymous. They were asked not to communicate with any of the other participants and not to open 
their booklets or turn a page of the booklets until instructed to do so by the experimenter. In a procedure similar to that used by Petty and colleagues (e.g., Petty \& Cacioppo, 1979), subjects then were told that the Psychology Department was cooperating with the University in doing a survey about students' opinions on an important issue. They were told that their opinions would be carefully considered by the University, and that a final decision on the issue would be aided by their responses. ${ }^{1}$

Warning induction. On the first page, subjects in warned groups were informed that the University was considering the adoption of a new policy that required senior students to take a comprehensive exam in their declared major. A satisfactory passing grade exam would be required for graduation. Subjects in unwarned groups were only informed that the University was considering adoption of a new policy on evaluation of students' academic performance.

Manipulation of personal involvement. On the same page, subjects in high personal involvement conditions read that the policy, if adopted, would be effective immediately, so it would affect most students then at the University. Subjects in low personal involvement conditions were informed that the policy would not affect anyone, because even if adopted, it would not be effective until the 1995 school year (the study was conducted in 1988). All subjects then were asked to listen to an audiotape of a faculty member advocating the adoption of the policy.

Distraction task. Immediately after the warning and involvement manipulations, subjects in distraction conditions were instructed to complete a distraction task. This task consisted of completing a series of verbal and arithmetic "progressions;" in our many uses of it, the task has proven to be quite involving. Subjects in undistracted conditions were told to do nothing but sit quietly. Three minutes passed. During this interval, the experimenter set up an audio tape recorder.

Message. All subjects heard a message, which lasted about 3 minutes, immediately after the distraction manipulation. In the message, a male speaker identified himself as a faculty member in the College of Education and a member of a faculty committee on Academic Affairs. The speaker went on to note declining trends in academic performance and successful job placements. The Committee, the faculty member reported, was considering the senior exams as a possible solution to the problem. The arguments (inspired by, and partially adapted from Petty \& Cacioppo, 1977) given for the exams can be paraphrased as follows: (a) students will spend more time on coursework because they know that they will have to retain it past the end of a semester; (b) top companies will come to recruit employees because they will have some quality assurance; (c) data show that starting salaries of students who come from schools with the exams are higher than those from schools that do not have the exams; (d) prestige graduate and professional programs prefer students from schools that have comprehensive exams; (c) faculty members who took such exams found them very helpful; (f) institution of exams might make a political impression on legislators concerned with standards or quality, leading to increases in appropriations. The speaker ended his talk with a short summary statement of the arguments. ${ }^{2}$

Dependent measures. Immediately after listening to the message, all subjects were asked to turn to the next page in their booklet and respond to three questions: (1) "To what extent do you agree with the recorded message on the adoption of senior comprehensive exams at OU?" (2) "What is your position on the adoption of the exams?" (3) "The recorded message was very persuasive." All responses were made on 9-point Likert-format

1 This cover story may have, itself, stimulated some involvement in the issue and task. However, as the data eventually confirmed, the cover story only produced a minimum platform of involvement upon which the involvement manipulation could be added.

${ }^{2}$ Transcripts of the complete texts of the statements for both experiments are available from either of the first two authors. 


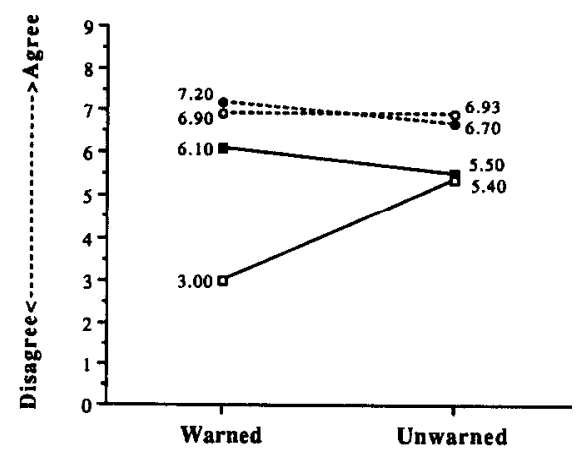

Fig. 1. Experiment 1: Mean responses to attitude scale measures. ( $\square$ ) Distracted/high, $(\odot)$ distracted/low, ( $\square$ ) undistracted/high, $(O)$ undistracted/low.

scales, where 1 indicated "strongly disagree," and 9 indicated "strongly agree." All subjects then were instructed to turn to the last page of their booklets. Using a typical cognitive response procedure (Brock, 1967; Greenwald, 1968; Petty et al., 1976), subjects were given $3 \mathrm{~min}$ to engage in thought-listing.

\section{Results}

Six subjects were excluded from analyses because they failed to follow instructions (e.g., failed to respond to an item or items). A $2 \times 2 \times 2$ (warning $\times$ distraction $\times$ involvement) analysis of variance (ANOVA) was performed on the attitude scale measures using the remaining 80 subjects ( 10 subjects per cell).

Attitude scale measure. The three attitude scales showed similar patterns of results and were highly correlated with each other. A coefficient $\alpha$ of .89 was obtained, suggesting that the three scales constitute a single coherent measure. Thus, a single attitude scale variable was created by summing the scale and dividing by three, across subjects. The means for each cell using this measure are presented in Fig. 1. The ANOVA revealed several significant effects. There were two main effects: Distracted subjects were less resistant, compared with the undistracted, to the persuasive communication, $F(1,72)=13.40, p<.001$; and, subjects in high involvement conditions showed more resistance to the message than their low involvement counterparts, $F(1,72)=75.08, p<, 001$. The following two-way interactions were also found: Distraction $\times$ warning, $F(1,72)$ $=15.67, p<.001$, distraction $\times$ involvement, $F(1,72)=12.33, p<$ .001 , and warning $\times$ involvement, $F(1,72)=6.45, p<.02$. Specifically, the warning effect was elevated in undistracted conditions as well as in high involvement conditions, and distraction had more impact on high involvement subjects than low involvement subjects. The three-way interaction of distraction $\times$ warning $\times$ involvement was also significant, $F(1,72)=7.64, p<.01$. Figure 1 shows that when subjects were not 

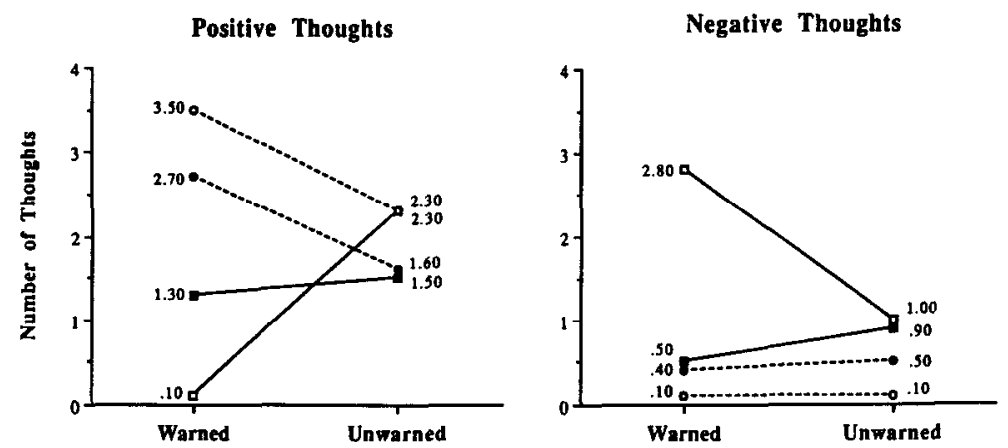

Fig. 2. Experiment 1: Mean positive and negative thoughts. (G) Distracted/high, (O) distracted/low, $(\square)$ undistracted/high, $(O)$ undistracted/low.

personally involved, neither distraction nor warning had significant impact on their resistance to the persuasive appeal. In contrast, highly involved subjects were more likely to resist the appeal, especially when they were not distracted following the warning of the message contents (warned high involvement-distracted $M=6.10$, vs warned high involvement-undistracted $M=3.00 ; p<.01$, Tukey HSD critical value $=1.64$ ).

Thought listing. The subjects' postmessage thoughts and ratings were evaluated by two naive judges. The judges agreed on $99 \%$ of subjects' classifications. Figure 2 shows the means of negative and positive thoughts in various conditions.

The results of an ANOVA on positive thoughts showed that subjects in low involvement conditions $(M=2.53)$ had more positive thoughts than those in high involvement conditions $(M=1.30), F(1,72)=7.87$, $p<.01$. A two-way interaction, warning $\times$ involvement, indicated that involved subjects had fewer positive thoughts, compared with the uninvolved subjects, especially in warned conditions, $F(1,72)=7.24, p<$ .01 (warned low involvement $M=3.10$, vs warned high involvement $M=.70 ; p<.01$, Tukey HSD critical value $=1.97$ ).

The results for negative thoughts indicated that involved subjects $(M=$ 1.30) generated more negative thoughts than their uninvolved counterparts $(M=.28), F(1,72)=20.53, p<.001$. A two-way interaction of distraction $\times$ warning showed that warned subjects had more negative thoughts if they were not distracted, $F(1,72)=6.46, p<.02$. Another two-way interaction was found for distraction $\times$ involvement, $F(1,72)$ $-11.74, p<.01$. Involved subjects showed more negative thoughts, compared with the uninvolved, only when they were not distracted. A three-way interaction of distraction $\times$ warning $\times$ involvement, $F(1,72)$ $=5.39, p<.03$, revealed that subjects in high involvement conditions had more negative thoughts than those in low involvement conditions, especially when they were not distracted after forewarning (warned high 
involvement-undistracted $M=2.80$, vs warned high involvement-distracted $M=.50$; warned high involvement-undistracted $M=2.80$, vs unwarned high involvement-undistracted $M=1.00 ; p<.01$, Tukey HSD critical value $=1.64$ )

\section{Discussion}

The results of Experiment 1 provide support for the counterargumentation hypothesis. Forewarning under conditions of high involvement produced resistance when subjects were able to develop counterarguments to the anticipated message (i.e., undistracted subjects). High involvement subjects who were distracted between warning and message, and who were thus unable to develop counterarguments, were less resistant and were persuaded to the same degree as those subjects were not forewarned. The thought-listing data in high involvement conditions clearly show the expected levels and directions of cognitive activity. In warned-undistracted conditions, there are virtually no positive thoughts, but many negative thoughts. Warned-distracted and unwarned-distracted subjects showed approximately the same pattern of activity, with positive thoughts outnumbering negative thoughts by about the same amount.

Let us consider now the results from low involvement conditions. In low involvement conditions, message recipients presumably use persuasion heuristics. In this case, some heuristic (e.g., expertise is one possibility; Chaiken et al., 1989) apparently resulted in a level of confidence in attitude that was well above sufficiency criteria. The attitude scale measures indicate that low involvement subjects were susceptible to the persuasive appeal in all conditions, and in all conditions, they were more persuaded than high involvement subjects. The thought-listing data show a differential impact of the independent variables. First, distraction seems to have generally interfered with cognitive activity: Fewer positive thoughts were listed when subjects were distracted. Also, warned subjects produced more positive thoughts than unwarned subjects, at both levels of distraction. Overall, however, variations in cognitive activity did not add anything to already confident opinions.

\section{EXPERIMENT 2}

Under conditions of high involvement, central route or systematic processing of issue-relevant arguments may increase subsequent agreement with the message. However, highly involved subjects who have been forewarned and not distracted might not exhibit this effect because they have prepared counterarguments. A sufficient level of confidence in one's judgment may have already been reached through the anticipation of arguments and counterarguments.

Messages containing weak arguments generally result in less persuasion when elaborative processing occurs than that found under conditions of 
low involvement when heuristic processing occurs and weak arguments do not have an influence. However, the recent meta-analysis by Johnson and Eagly (1989) found that differences in persuasion resulting from the processing of weak arguments under high and low involvement conditions are not reliably found. It was suggested by Johnson and Eagly that under conditions of high involvement, weak arguments provide inadequate information to reach a criteria of sufficient confidence in one's attitude. In such cases, one's attitude is likely to remain the same as it was before exposure to the message instead of becoming more negative. Crossing argument strength and involvement with forewarning may help to clarify this process by providing an alternative means of attainment of sufficient confidence through forewarning and counterargumentation. To the three factors of Experiment 1, we added a message strength variable.

\section{Method}

Manipulation of message strength. In developing the arguments for the message, 60 different members from the same subject population as Experiment 1 were recruited. After a brief explanation of "senior comprehensive exams," the students were instructed to pretend to favor the adoption of the requirement for graduation and to generate, individually, various plausible reasons why the senior comprehensive exams should be instituted at the University. Thirty 7 -inch horizontal lines, each about .7 inch from the one above, created 15 boxes in which subjects were to write their reasons. This task was conducted in three separate sessions, with 10 subjects in each session. Subjects were encouraged to generate as many reasons as possible in $10 \mathrm{~min}$. The remaining 30 subjects were presented with the generated arguments and were asked to rate them for strength. The ratings ranged from 1 (least convincing) to 9 (most convincing). Based on these ratings, arguments with high ratings were selected to constitute a strong message advocating the requirement of senior comprehensive exams; while arguments with low ratings were selected to constitute a weak message advocating the adoption of the policy. Each of the messages was about 450 words and about $3 \mathrm{~min}$ long on audiotape. Another set of 10 subjects were used to test the persuasiveness of the two versions of message on a 9-point Likert-format scale, where 1 indicated "not persuasive at all," and 9 indicated "very persuasive." With the presenting order counterbalanced, the subjects' mean ratings for the strong and weak messages were 7.40 and 3.50 , respectively, $t(9)=1.90, p<.05$.

Subjects. The subjects were 169 undergraduates from the same pool as Experiment 1, who participated as one option of a research familiarization requirement.

Design. The design was a $2 \times 2 \times 2 \times 2$ factorial with two levels of involvement (high and low), two levels of distraction (distracted and undistracted), two levels of warning (warned and unwarned), and two levels of message strength (strong and weak). Subjects were assigned at random to 1 of the 16 conditions.

Procedure. The procedure of Experiment 2 was virtually the same as that of Experiment 1 , except for the addition of a manipulation of message strength. Running sessions were homogeneous with respect to the distraction and message strength variables; within sessions, subjects were randomly assigned to warning and involvement conditions. The strong message included the arguments from Experiment 1 . The subjects in weak message conditions heard the following arguments: (a) Comprehensive exams would encourage class attendance, and increased attendance would stimulate instructors; (b) the exams would ensure consistency of material covered/presented in courses among instructors; (c) the exams would "weed out" those who had been getting by through cheating; (d) the stress caused by the exams 

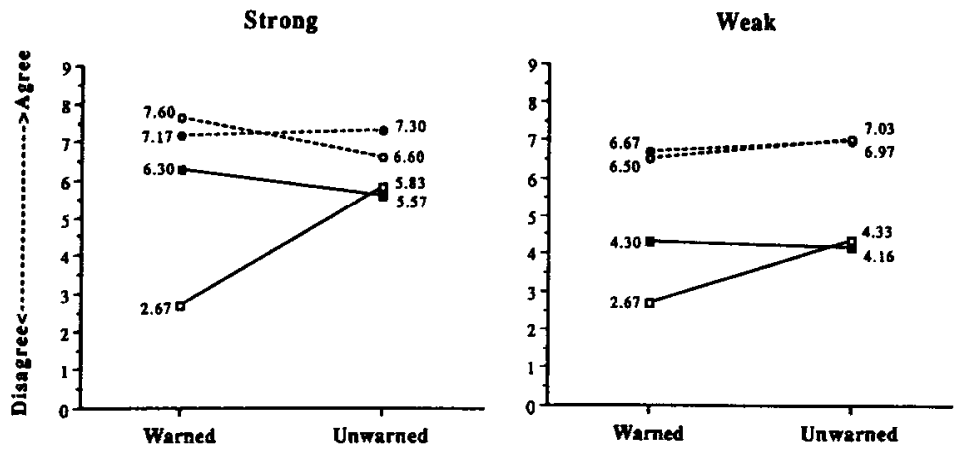

Fig. 3. Experiment 2: Mean responses to attitude scale measures. (ם) Distracted/high, (๑) distracted/low, ( $\square$ ) undistracted/high, $(O)$ undistracted/low.

would be useful in helping students learn how to handle stress; (e) students would be more likely to develop superior study skills and mnemonics if they know they will have to retain the material for longer; (f) the exams would attract better faculty to the University.

Immediately after message exposure, all subjects were instructed to turn to the next page of their booklets and respond to the same three questions as those of Experiment 1. The experiment was completed when all subjects finished writing their postmessage thoughts in $3 \mathrm{~min}$.

\section{Results}

Data from 9 subjects were excluded from analyses because these subjects failed to follow instructions. A $2 \times 2 \times 2 \times 2$ (warning $\times$ distraction $x$ involvement $x$ strength) ANOVA was performed on the three dependent variables using the remaining 160 subjects ( 10 subjects per cell).

Attitude scale measure. The data from the three attitude scales were combined in the same way as in Experiment 1 (coefficient $\alpha=.95$ ). The means for the resulting attitude scale measure are presented in Fig. 3. The ANOVA revealed several significant effects. Warned subjects were more resistant to the message than unwarned subjects, $F(1,144)=12.24$, $p<.001$. The distracted were less resistant, compared with the undistracted, to the persuasive communication, $F(1,144)=16.39, p<.001$; subjects in high involvement conditions showed more resistance to the message than their low involvement counterparts, $F(1,144)=281.37$, $p<.001$, and subjects yielded more agreement to the strong message than to the weak one, $F(1,144)=30.65, p<.001$. The following twoway interactions were found: Distraction $\times$ warning, $F(1,144)=17.76$, $p<.001$; distraction $\times$ involvement, $F(1,144)=15.51, p<.001$; warning $\times$ involvement, $F(1,144)=9.35, p<.01$; and involvement $\times$ argument strength, $F(1,144)=6.56, p<.02$. Specifically, the warning effect was evident only in undistracted conditions as well as in high involvement conditions, and the distraction effect was significant only when the subjects were highly involved in the topic issue. A three-way interaction of dis- 
traction $\times$ warning $\times$ involvement was significant, $F(1,144)=27.10$, $p<.001$. Figure 3 shows that, as was found in Experiment 1, when subjects were not personally involved, neither distraction nor warning had significant impact on their resistance to the message. In contrast, highly involved subjects were more likely to resist the appeal when they were not distracted following the warning of the message contents (warned high involvement-undistracted $M=2.67$, vs warned low involvement-undistracted $M=7.05, p<.01$, Tukey HSD critical value $=1.24)$.

Finally, a four-way interaction of distraction $\times$ warning $\times$ involvement $\times$ strength was found, $F(1,144)=6.85, p<.01$. The distraction $\times$ warning $x$ involvement interaction was more pronounced when the arguments were strong rather than weak: As Fig. 3 indicates, subjects in high involvement conditions were better able to differentiate the strength of the message (i.e., the strong message was more persuasive than the weak one) than those in low involvement conditions; however, this was true only when the subjects were unwarned or were warned but distracted; when warning was not followed by distraction, the subjects in high involvement conditions showed extreme resistance to the strong message as well as the weak one. In low involvement conditions subjects were more persuaded in general, but, interestingly, when warned subjects were not distracted, they seemed to agree more with the strong message than with the weak one (the Tukey HSD critical value, at $p<.05$, for distraction $\times$ warning $\times$ involvement $\times$ strength cells $=1.47$; cell means are in Fig. 3).

Thought listing. The subjects' postmessage thoughts and ratings were evaluated by two naive judges. Thoughts were classified into three categories: Negative thoughts (i.e., opposed to the advocated position), positive thoughts (i.e., in favor of the advocated position), and neutral thoughts (i.e., unrelated thoughts or related thoughts of unspecified favorability). The judges agreed on $\mathbf{9 8 . 8 5 \%}$ of subjects' classifications. Figure 4 shows the means of negative and positive thoughts in various conditions.

Analyses of variance were performed on negative and positive thoughts separately. The results on negative thoughts showed all the four main effects: The undistracted $(M=1.16)$ had more negative thoughts than the distracted $(M=.74), F(1,144)=10.70, p<.01$; the warned $(M$ $=1.11)$ generated more negative thoughts than the unwarned $(M=.79)$, $F(1,144)=6.26, p<.02$; compared with those in low involvement conditions $(M=.34)$, subjects in high involvement conditions $(M=$ 1.56) showed more negative thoughts, $F(1,144)=88.93, p<.001$; the weak message $(M=1.14)$ drew more negative thoughts than the strong one $(M=.76), F(1,144)=8.33, p<.01$. A two-way interaction of distraction $\times$ warning showed that warned subjects had more negative thoughts if they were not distracted, $F(1,144)=14.81, p<.001$. Another 
Strong

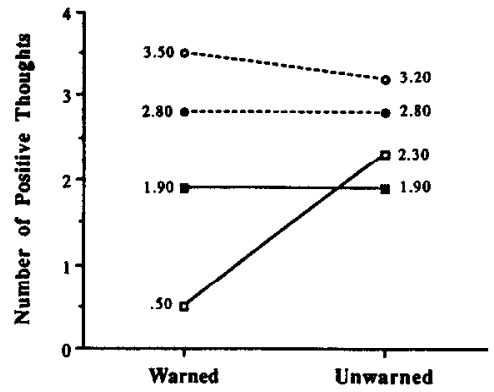

Strong

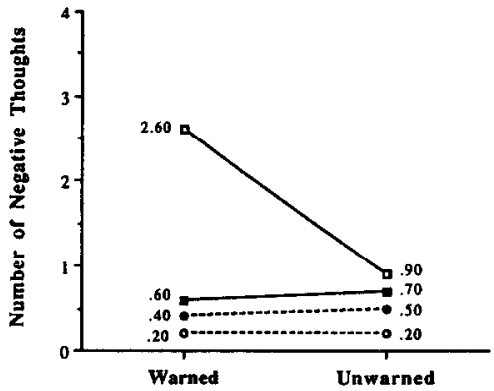

Weak

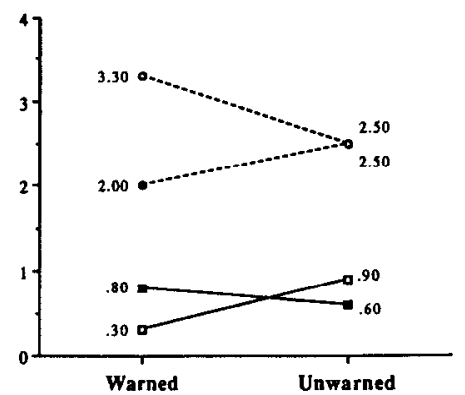

Weak

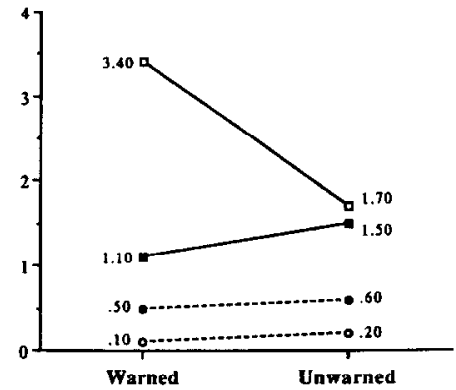

Fig. 4. Experiment 2: Mean positive and negative thoughts. (ש) Distracted/high, (O) distracted/low, $(\square)$ undistracted/high, $(O)$ undistracted/low.

two-way interaction was found in distraction $\times$ involvement, $F(1,144)$ $=33.33, p<.001$, suggesting that high involvement subjects showed more negative thoughts, compared with low involvement subjects, especially when they were not distracted. A two-way interaction of warning $\times$ involvement, $F(1,144)=9.48, p<.01$, suggested that warning caused more negative thoughts only in high involvement conditions. Another two-way interaction of strength $\times$ involvement, $F(1,144)=7.26, p<$ .01 , indicated that a weak message led to negative thoughts only if the subjects were highly involved. A three-way interaction of distraction $\times$ warning $\times$ involvement, $F(1,144)=13.37, p<.001$, revealed that subjects in high involvement conditions had more negative thoughts than those in low involvement conditions, especially when they were not distracted after warning.

The results of the ANOVAs on positive thoughts showed that subjects in low involvement conditions ( $M=2.83$ ) had more positive thoughts than those in high involvement conditions $(M=1.15), F(1,144)=70.94$, $p<.001$. It was also found that after listening to the strong message $(M=2.36)$, subjects had more positive thoughts than those in the weak 
message conditions $(M=1.61), p<.001$. A two-way interaction of distraction $\times$ involvement indicated that, in low involvement conditions, the undistracted generated more positive thoughts than the distracted, $F(1,144)=5.12, p<.03$. A three-way interaction of distraction $\times$ warning $x$ involvement suggested that in high involvement conditions, warned subjects had less positive thoughts if they were not distracted, whereas warned subjects in low involvement conditions showed more positive thoughts when they were not distracted, $F(1,144)=6.97, p<$ .01 .

\section{Discussion}

Again, the counterargumentation hypothesis was supported. In high involvement conditions, resistance to persuasion was evident when subjects were forewarned and not distracted, regardless of message strength. When subjects were not forewarned, and when subjects were forewarned but distracted, argument strength accounted for differences in susceptibility: Strong arguments led to more persuasion than weak arguments. The cognitive response data for high involvement conditions showed few positive and many negative thoughts when subjects were forewarned and not distracted, and weak arguments led to more negative thoughts than strong arguments (with no impact of strength, possibly due to floor effects). When subjects were unwarned and undistracted, or distracted, argument strength accounted for all differences, with strong arguments producing more positive thoughts than weak arguments, and weak arguments producing more negative thoughts than strong arguments.

In low involvement conditions, persuasion as indicated by the attitude scale measures was almost uniformly high; as in Experiment 1, cognitive responding varied as a function of the other independent variables. Few negative thoughts were generated, ragardless of levels of distraction, warning, or argument strength. Generally, strong arguments led to more positive thoughts than weak arguments, and distraction led to fewer positive thoughts than no distraction. Distraction led to fewer positive thoughts following weak arguments when subjects were warned than when subjects were warned and undistracted. That is, distraction seems to have had a negative impact on positive thought generation when low involvement subjects were forewarned and arguments were weak. However, as in Experiment 1, confidence was already sufficiently high, and, as the attitude scale measure shows, variations in cognitive activity did not add or detract from that confidence.

\section{GENERAL DISCUSSION AND CONCLUSIONS}

In both experiments, when involvement was high, and cognitive responding was not interfered with by distraction, warned subjects were more resistant to the persuasive message than unwarned subjects. In 
contrast, warning and distraction effects were not noticed in low involvement conditions. This finding provides strong support for the counterargumentation hypothesis, and it also suggests that warning of an impending counterattitudinal message induces resistance to the appeal only when the message topic is highly involving and important to the recipients.

Subjects in low involvement conditions were more persuaded overall than their high involvement counterparts. However, when low involvement subjects were forewarned and not distracted, they seemed to process the content of the message enough to make some discrimination of argument strength; the strong message produced more agreement, and was rated more favorably than the weak one. This may be because the strong arguments were a closer match to the expectations created by forewarning than weak arguments.

The comparisons of positive and negative thoughts allows us to verify subjects' resistance to the persuasive appeal in various conditions. The results clearly showed that persuaded subjects tended to have more positive thoughts after exposure to the persuasive communication than those who were resistant to the appeal. For example, the persuaded subjects in low involvement conditions showed more positive thoughts but fewer negative thoughts than those in high involvement conditions, where resistance to persuasion was observed. It is also important to note that in high involvement conditions, unwarned subjects, and warned but distracted subjects, showed more positive thoughts and fewer negative thoughts than the warned but undistracted subjects.

Petty and Cacioppo's (1977) thought-listing method of investigating cognitive responding following forewarning has been criticized for not providing direct evidence of cognitive counterargumentation following forewarning because of possible demand characteristics (e.g., Miller \& Baron, 1973; Orne, 1962). The distraction method and postmessage thoughts measurement employed in this study provide support for the counterargumentation hypothesis.

In low involvement conditions, we found highest the levels of persuasion overall and the highest levels of cognitive activity. This is most consistent with a view that holds that an available heuristic (e.g., expertise) provided sufficient confidence in a favorable attitude. The heuristic may also have incidentally activated knowledge structures, making relevant thoughts available. These thoughts may not have been carefully considered at the time attitude scale choices were made, but they were available when subjects were asked to list thoughts. The available thoughts, those in the network activated by the heuristic, are likely to be consistent with the heuristic; in our case, in favor of the advocacy (thus the listing of many positive thoughts, and few, if any, negative thoughts). Generation, then, in low involvement conditions, may not be the "on-line" evaluative processing it is in high involvement conditions, but a process of "reading off' of thoughts from a recently activated network. 


\section{Persuasive?}

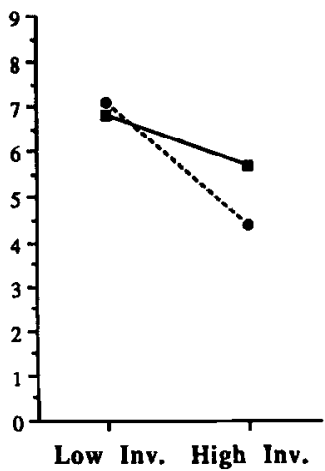

Fig. 5. Experiment 2: Argument strength $\times$ involvement, unwarned-undistracted conditions only. (ם) Strong, (O) weak.

With respect to involvement, our pattern of results may be informative regarding a recent issue in the persuasion literature. Our issue was the same as that used by Petty and Cacioppo (1979), and would thus be considered to be "outcome relevant" by Johnson and Eagly $(1989,1990)$. As such, there should be little cognitive activity in low involvement conditions, or at least, little difference in cognitive activity relative to high involvement conditions. That there was a great deal of cognitive activity suggests that, as Petty and Cacioppo (1990) have claimed, a wealth of concepts can be made available to subjects if they have a stake in the situation (whether value- or outcome-relevant).

Our data also reinforce Petty and Cacioppo's (1990) point that, at high levels of involvement, other elements of the persuasion setting (like argument strength) determine persuasion by creating processing biases. Figure 5 is illustrative. It shows just the attitude scale results for the argument strength $x$ involvement interaction for the unwarned-undistracted conditions of Experiment 2. This figure very closely follows that of Petty and Cacioppo $(1986,1990)$ for unfavorably biased processing.

As we said at the outset, and as our findings confirm, forewarning situations can be quite complex. However, as we and other investigators have tried to demonstrate, forewarning adds something "special" to persuasion settings that goes beyond the specifics of forewarning itself; it informs us about key cognitive and motivational processes and ways these kinds of processes interact.

\section{REFERENCES}

Apsler, R., \& Sears, D. O. (1968). Warning, personal involvement, and attitude change. Journal of Personality and Social Psychology, 9, 162-166.

Brock, T. C. (1967). Communication discrepancy and intent to persuade as determinants 
of counterargument production. Journal of Experimental Social Psychology, 3, 269309.

Cacioppo, J. T., \& Pelly, R. E. (1979). Attitudes and cognitive responses: An electrophysiological approach. Journal of Personality and Social Psychology, 37, 2181-2199.

Chaiken, S. (1980). Heuristic versus systematic information processing and the use of source versus message cues in persuasion. Journal of Personality and Social Psychology, 39, $752-756$.

Chaiken, S. (1987). The heuristic model of persuasion. In M. Zen, J. Olson, \& C. P. Herman (Eds.), Social influence: The Ontario symposium (Vol. 5, pp. 3-39). Hillsdale, $\mathrm{NJ}$ : Erlbaum.

Chaiken, S., Liberman, A., \& Eagly, A. H. (1989). Heuristic and systematic information processing within and beyond the persuasion context. In, J. Bargh \& E. T. Higgens (Eds.), Unintended thought (pp. 212-252). New York, NY: Guilford Press.

Chen, H. C., \& Reardon, R. (1987, April). Expertise, forewarning, cognitive responding, prior knowledge, and resistance to persuasion. Southwestern Psychological Association, New Orleans, LA.

Cialdini, R. B., Levy, A., Herman, P., Kozlowski, L., \& Petty, R. E. (1976). Elastic shifts of opinion: Determinants of direction and durability. Journal of Personality and Social Psychology, 34, 663-672.

Cialdini, R. B., \& Petty, R. E. (1981). Anticipatory opinion effects. In R. Petty, T. Ostrom, \& T. Brock (Eds.), Cognitive responses in persuasion (pp. 217-235). Hillsdale, NJ: Erlbaum.

Cooper, J., \& Jones, R. A. (1970). Self-esteem and consistency as determinants of anticipatory opinion change. Journal of Personality and Social Psychology, 14, 312-320.

Deutsch, M., \& Gerard, H. B. (1955). A study of normative and informational social influences upon individual judgment. Journal of Abnormal and Social Psychology, 51, $629-636$.

Festinger, L., \& Maccoby, N. (1964). On resistance to persuasive communications. Journal of Abnormal and Social Psychology, 68, 359-366.

Freedman, J. L., \& Sears, D. O. (1965). Warning, distraction and resistance to influence. Journal of Personality and Social Psychology, 1, 262-266.

Greenwald, A. G. (1968). Cognitive learning, cognitive responses to persuasion, and attitude change. In A. Greenwald, T. Brock, \& T. Ostrom (Eds.), Psychological foundations of attitudes (pp. 148-170). New York: Academic Press.

Harkins, S. G., \& Petty, R. E. (1981). The multiple source effect in persuasion: The effects of distraction. Personality and Social Psychology Bulletin, 7, 627-635.

Hass, R. G., \& Grady, K. (1975). Temporal delay, type of forewarning, and resistance to influence. Journal of Experimental Social Psychology, 11, 459-469.

Johnson, B. T., \& Eagly, A. H. (1989). Effects of involvement on persuasion: A metaanalysis. Psychological Bulletin, 106, 290-314.

Johnson, B. T., \& Eagly, A. H. (1990). Involvement and persuasion: Types, traditions, and the evidence. Psychological Bulletin, 107, 375-384.

Kiesler, C. A. (1971). The psychology of commitment. New York: Academic Press.

McGuire, W. J. (1985). Attitudes and attitude change. In G. Lindzey \& E. Aronson (Eds.), Handbook of social psychology (Vol. 2, pp. 233-346). New York: Random House.

McGuire, W. J., \& Millman, S. (1965). Anticipatory belief lowering following forewarning of a persuasive attack. Journal of Personality and Social Psychology, 2, 471-479.

Miller, N., \& Baron, R. S. (1973). On measuring counterarguing. Journal for the Theory of Social Behavior, 3, 101-118.

Mills, J., \& Aronson, E. (1965). Opinion change as a function of the communicator's attractiveness and desire to influence. Journal of Personality and Social Psychology, 1, 173-177. 
Orne, M. T. (1962). On the social psychology of the psychological experiment: With particular reference to demand characteristics and their implications. American Psychologist, 17, 776-783.

Papageorgis, D. (1968). Warning and persuasion. Psychological Bulletin, 70, 271-282.

Petty, R. E., \& Cacioppo, J. T. (1977). Forewarning, cognitive responding, and resistance to persuasion. Journal of Personality and Social Psychology, 35, 645-655.

Petty, R. E., \& Cacioppo, J. T. (1979). Effects of forewarning of persuasive intent and involvement on cognitive responses and persuasion. Personality and Social Psychology Bulletin, 5, 173-176.

Petty, R. E., \& Cacioppo, J. T. (1984). The effects of involvement on responses to argument quantity and quality: Central and peripheral routes to persuasion. Journal of Personality and Social Psychology, 46, 69-81.

Petty, R. E., \& Cacioppo, J. T. (1986). The elaboration likelihood model of persuasion. In L. Berkowitz (Ed.), Advances in experimental social psychology (Vol. 19). New York: Academic Press.

Petty, R. E., \& Cacioppo, J. T. (1990). Involvement and persuasion: Tradition versus integration. Psychological Bulletin, 107, 367-374.

Petty, R. E., Wells, G. L., \& Brock, T. C. (1976). Distraction can enhance or reduce yielding to propaganda: Thought disruption versus effort justification. Journal of Personality and Social Psychology, 34, 874-884. 